\title{
Multiple Correspondence Analysis, newspaper discourse and subregister
}

\section{A case study of discourses of Islam in the British press}

\author{
Isobelle Clarke, Tony McEnery ${ }^{1,2}$ \& Gavin Brookes ${ }^{1}$ \\ ${ }^{1}$ Lancaster University $\mid{ }^{2}$ Xian Jiaotong University
}

This article introduces a new method for grouping keywords and examines the extent to which it also allows analysts to explore the interaction of discourse and subregister. It uses the multivariate statistical technique, Multiple Correspondence Analysis, to reveal dimensions of keywords which cooccur across the texts of a corpus. These dimensions are then interpreted in terms of the discourses to which they contribute within the data, thus forming the basis of a corpus-assisted discourse analysis. The approach is demonstrated through analysis of the discourses that are used to represent Muslims and Islam in a corpus of UK national newspaper articles published on these topics spanning 2010-2019. The approach reveals an interaction between discourse and subregister, hence this article argues for the need for (corpus-assisted) discourse analysts to account for subregister as a level of meaningful variation when analysing press discourse.

Keywords: keyword analysis, Multiple Correspondence Analysis, newspaper discourse, Islam

\section{Introduction}

This paper takes a keyword approach to exploring representations of Muslims and Islam in UK newspapers. Hence this paper examines a socially important form of text, newspaper articles, which are commonly analysed in corpus-assisted discourse studies. Our motivation is twofold. First, we wish to refresh on-going work on this topic by Baker et al. (2013) and Baker and McEnery (2019). Secondly, we explore a new way of examining keywords in discourse analysis using the multivariate statistical technique, Multiple Correspondence Analysis (MCA) to reveal

Appendix available from https://doi.org/10.1075/rs.20024.cla.additional https://doi.org/10.1075/rs.20024.cla | Published online: 25 May 2021 Register Studies 3:1 (2021), pp. 144-171. issn 2542-9477| e-issn 2542-9485

() Available under the CC BY 4.0 license. ( ) John Benjamins Publishing Company 
dimensions of co-occurring keywords. In doing so, we observed that some newspaper subregisters intersect with discourses around Muslims and Islam.

While newspaper articles represent one of the four major registers of English presented by Biber et al. (1999), they also exhibit variation in terms of the subregisters they contain (Biber \& Conrad, 2019:112-117; for work comparing newspaper subregisters see Bednarek 2006; Biber \& Gray 2013; Carter 1988). Thus, in this paper, based on our analysis, we suggest that an interaction between subregister and discourse may be possible and could be approached using the dimension reduction method, MCA, by reasoning, as Biber and Conrad (2019) do, that because the identification of dimensions are independent of register, dimensions can be used to explore variation amongst subregister categories within a corpus. Such variation, in our case, is relevant to keywords. Ideally, this interaction should be explored systematically by including corpus meta-data related to subregister as a supplementary variable in the MCA, which would reveal the associations of the subregisters to the dimensions, enabling the assessment of the link between discourse and subregister. Our approach to exploring subregister here, however, is constrained as our corpus does not explicitly mark subregisters. Moreover, the dataset is too large for us to code this information by hand. Hence, in this paper we show how, as a by-product of the approach to keyword analysis taken, we may facilitate the identification of subregister effects in discourse during the qualitative analysis of the MCA results - i.e., by examining texts associated with the dimensions.

\section{Islam in the press: Existing research and the recent context}

Baker et al. (2013) conducted a major study using a corpus-based Critical Discourse Analysis to interrogate the representational discourses around Islam and Muslims in a corpus of UK national newspaper articles on this topic published between 1998 and 2009 (inclusive). Baker and McEnery (2019) then completed a follow-up study of the period 2010 to 2014 (inclusive), sampling articles using the same search-terms and criteria as Baker et al. (2013) for data comparability. ${ }^{1}$

1. The search-terms, in the notation used by the LexisNexis news consolidator which was used to build our corpora, is "Alah OR Allah OR ayatollah! OR burka! OR burqa! OR chador! OR fatwa! OR hejab! OR imam! OR islam! OR Koran OR Mecca OR Medina OR Mohammedan! OR Moslem! OR Muslim! OR mosque! OR mufti! OR mujaheddin! OR mujahedin! OR mullah! OR muslim! OR Prophet Mohammed OR Q'uran OR rupoush OR rupush OR sharia OR sharia OR shia! OR shi-ite! OR Shi'ite! OR sunni! OR the Prophet OR wahabi OR yashmak! AND NOT Islamabad AND NOT shiatsu AND NOT sunnily". 
Baker and McEnery (2019) reported both stability and change across the two periods (1998-2009/2010-2014), though stability was the exception and more had changed than remained stable. These studies provide an important framing for our research. They present results that we can build upon, yet they also impose limitations on what we may do. Importantly, we are constrained to taking their basic approach to corpus collection and keyness if we are to compare our results to theirs, or if we are to claim that we have extended those studies through time. Hence in this paper we follow their basic keywords approach, but we then take a new approach to exploring and grouping those keywords, as will be discussed in the next section. Alternative approaches to extracting keywords, and how our study may be extended, are considered at the end of this paper.

Before introducing our data, we should consider an important aspect of the 2013 and 2019 studies - subregister. In both studies, the authors claimed that distinct subregisters were linked to particular discourses. For example, opinion columns represented 'one way in which more negative constructions of Muslims are legitimated' (Baker et al. 2013: 189), while overtly Islamophobic discourse was linked to readers' letters and texts, with these subregisters constituting 'effective vehicles for the spread of generalising, negative discourses' (Baker et al. 2013: 190). Subregister seemingly plays an important role in discourse, yet its discovery in these studies resulted from close reading, as the inductive keyword analyses were based on texts that did not distinguish subregisters apart. In such unstructured collections, can keywords be grouped into dimensions which may, where relevant, aid analysts in discovering groups of texts which represent discourses that are linked to specific subregisters? In this paper, we linked keyword analysis to MCA in an attempt to group keywords into dimensions based on their cooccurrence across the texts of the corpus, and hence to permit the identification of texts that are strongly associated with the specific keyword co-occurrence patterns represented in the dimensions. Our hypothesis was that the grouping of the keywords would aid the process of corpus-assisted discourse analysis by automating an initial, meaningful grouping of keywords into dimensions coterminous with discourses. In addition to finding evidence to support this hypothesis, we also found that by grouping texts according to dimensions of keyword variation, the automated analysis serendipitously facilitated the identification of links to subregister and discourse. Thus, we hypothesise that this approach may provide substantial assistance to the discourse analyst in exploring the link between subregister and discourse where metadata does not allow that link to be explored more systematically. 


\section{Approach: Data, keyword co-occurrence and MCA}

This paper analyses a corpus representing UK press coverage of Islam and Muslims between 2010 and 2019 (inclusive). We employed the same search-terms as Baker et al. (2013:28) to build our corpus, as Baker and McEnery (2019) had, and downloaded all qualifying UK national newspaper ${ }^{2}$ articles published between 01.01.2015 and 01.12.2019 via LexisNexis. The resultant corpus contains 497,523 articles (395,930,045 words). As may be inferred, the texts in the corpus are typically short - in our corpus 398,606 articles were 1,000 words or less, with only 98,917 articles exceeding 1,000 words in length.

Using this corpus, we began the process of analysing representational discourses using keywords. Standard keyword tools can point analysts towards keywords which allow access to the discourses associated with some object of study (Baker et al. 2013). Yet aggregation is an issue entailed by the use of standard keyword approaches which contrast one dataset against another. The explicit and implicit structure that may be present in each dataset is, effectively, ignored. Where that structure exists explicitly in metadata, it is possible to achieve some degree of disaggregation by conducting multiple comparisons of structured subparts of each corpus. For example, Baker et al. (2013) undertook comparisons of their corpus's subparts (e.g. broadsheets and tabloids) to try to disaggregate their keyword results. That subdivision was enabled by metadata. Their analyses showed that individual keywords could relate to numerous discourses. Those discourses were aggregated in the set of keywords, but they represented an important, implicit, structuring of the data which analysts, through close reading and the use of other corpus-based tools, must disaggregate. Attempts to identify discrete discourses through some sort of clustering process, specifically topic modelling, have only demonstrated that topic modelling is not fit for the purpose of discourse analysis (Brookes \& McEnery 2019). Another persistent issue with keyword studies is their focus on presence rather than absence, yet absence can be as meaningful as presence in discourse analysis (Schroeter \& Taylor 2018) and patterns of presence and absence across a corpus may meaningfully interact (Partington 2014).

2. Newspapers included Daily Star Online, Daily Star Sunday, Daily Star, Express Online, Guardian.com, i-Independent Print Ltd, Independent Magazine, Independent Traveller, Independent.co.uk, MailOnline, mirror.co.uk, Sunday Express, Sunday Mirror, telegraph.co.uk, The Daily Mail, The Daily Mirror, The Daily Telegraph, The Express, The Guardian, The Independent on Sunday, The Independent, The Mail On Sunday, The Mirror, The News of the World, The Observer, The People, The Sun, The Sunday Telegraph, The Sunday Times, The Times. 
Our approach, keyword co-occurrence, largely addresses the issues of aggregation and absence. This new method groups keywords based on their cooccurrence across the texts of a corpus, with each subsequent set of keywords representing a distinct pattern of co-variation. The method is grounded in the notion of linguistic co-occurrence - that frequent patterns of co-occurring linguistic features tend to have at least one underlying communicative function (Biber 1988). Linguistic co-occurrence informs Multi-Dimensional Analysis (MDA) (Biber 1988) and short-text MDA (Clarke 2019), which identifies sets of lexical and grammatical features that co-occur often across the texts of a corpus. Standard MDA measures the relative frequencies of lexico-grammatical features and subjects these to a multivariate statistical technique called factor analysis (Biber 1988). Factor analysis identifies patterns across numerous measured variables which can be explained in terms of latent or underlying constructs.

However, standard MDA was not suitable for our study because of the nature of the data we were dealing with. MDA works with relative frequencies of linguistic features. Yet the relative frequencies of most grammatical features are typically only reliable estimates in text samples greater than 1,00o words (Biber 1993). Yet, as noted, the overwhelming majority of texts in our corpus are 1,000 words or less. Hence, we turned to short-text MDA which measures the presence or absence of features across the texts, allowing absence, presence and their relationship to one another to be accounted for. This information is then processed using MCA, which identifies and visualises relationships between three or more categorical variables. MCA was popularised by Benzécri (1979), who used it to analyse sociological data from questionnaires, as it can be used to observe relationships between individuals (e.g. people who answered questions similarly or dissimilarly), as well as between variables (i.e. which answers tend to be selected together, and which are rarely selected together).

MCA visualises the relationships between individuals and variables in terms of distance, producing two clouds of points, where the points on one cloud represent the individuals and the points on the other represent the categorical variables. The distance between each point is based on how similar they are in their distribution. For example, with Benzécri's questionnaire data, points representing people are closer in the space if they give the same responses to the questions, while points representing responses are closer if they distribute similarly across the people. So, if many people select the same responses, those responses are closer together in the space. MCA is used in short-text MDA much like factor analysis is used in standard MDA - to identify the major patterns of linguistic co-occurrence across texts. Conceptually, the method proposed here is similar to short-text MDA. However, rather than analyse lexical and grammatical features, we instead analyse keywords produced through keyness analysis. 
Given the central role that keywords have in our study, we will now summarize and contextualize the rationale for our methodological choices. We will describe how these were operationalized and make some initial observations about the limitations the approach taken, a theme which is returned to in Section 6.

This paper is part of a broader project examining the representation of Islam and Muslims in the UK press over time. The project has two aims. The first is covered by this paper; we wish to see whether the MCA approach can identify the dominant discourses of Islam and Muslims through keywords, according to their co-occurrence across the texts of the corpus, and to assess if this approach confirms, challenges or further illuminates the findings of Baker and McEnery (2019). The second goal, covered in Clarke et al. (forthcoming), builds upon the current paper by using the approach introduced here to track changes in press representations of Islam and Muslims over time.

Hence our broader project constrains our keyword extraction approach. Because we wish to achieve a close match to Baker and McEnery's study to assess if the MCA approach confirms their findings, we needed to extract keywords in a similar way. So following Baker and McEnery (2019), we used log-likelihood (Dunning 1993) as our keyword statistic, reducing our keyword lists by discarding keywords that did not have a log-likelihood value of 3.84 or above (ensuring our keywords had a p-value of <0.05). To prepare the data for the MCA approach in this study, we then eliminated keywords which did not occur in at least $5 \%$ of texts in the target corpus (providing an indicative dispersion threshold that any candidate keyword must pass) and reduced the keyword list further by applying an upper bound for dispersion (keywords must not occur in more than 95\% of texts).

One innovation we introduced relates to granularity: the extraction of keywords in Baker and McEnery (2019) was achieved at a very coarse level of granularity through the contrast of two time periods, i.e. 1998-2009 (Baker et al. 2013) and 2010-2014 (Baker \& McEnery 2019). A consequence of this is that, without the 1998-2009 corpus, we could not compute exactly the same keywords as Baker and McEnery (2019). We could not simply compare the 2010-2014 corpus with our 2015-2019 corpus as that would only enable us to achieve the broader project's second aim and not the assessment of the MCA approach. So, to achieve a close approximation of the keywords from the 2019 study, we divided both corpora by year, using each previous year as a reference corpus to the target corpus, which was the following year sub-corpus. For example, to obtain keywords for 2016 we compared this sub-corpus against the 2015 one. By dividing the corpus into yearly sub-corpora, we were, to the best of our ability, able to assess the aboutness of the 2010-2014 corpus; however, this is relative to each previous year within that corpus as opposed to articles published between 1998-2009. When compared with 
the keywords from Baker and McEnery (2019), we found many of the same keywords, but there are also discrepancies, some of which, we accept, are likely the result of this approach.

The consolidated keyword list includes 567 items (see Supplemental Materials - Appendix I). By combining the keyword lists into a single list, we are actively investigating how all the keywords co-occur across all the texts in the corpus, rather than just a subset of the keywords in a subset of the corpus. We appreciate that many may see the merging of the lists as implying that we are treating a sub-corpus's keyword list as representing the whole corpus. Instead, we are treating it as a possibility as opposed to disregarding it. Overall, our merged keyword lists represent a list of variables computed from the corpus reflecting the aboutness of particular years. We seek to uncover patterns of variation in the corpus according to these variables. As with any study investigating patterns of variation amongst variables, the approach will be limited according to which variables are included. This keyword extraction approach ignores words that are stable across all the years as they will not be identified via the keyword approach. Additionally, different keyword extraction techniques would likely produce somewhat different results. Consequently, the approach taken here is constrained by the project's broader aims and the previous study. Future research could explore different approaches, contrasting and comparing the results.

Having merged the keyword lists, the presence or absence of the keywords in each article across the corpus was recorded and analysed using a Perl program which ran through each file in the corpus and recorded, in a data matrix, whether, for each file, each keyword was present or absent. Table 1 is an excerpt of the data matrix. Each row is an article in the corpus, each column represents a keyword, and each cell reflects whether the given keyword is present or absent in the corresponding newspaper article in our corpus. Metadata for each article was added to the data matrix, including the publication date, newspaper name, and article length (in word tokens).

Table 1. Excerpt from the data matrix, indicating the presence (P) or absence (A) of keywords in corpus files

\begin{tabular}{llllllll}
\hline FILE & Able & About & Abu & According & Accused & Across & Act \\
\hline Express_2010_1.txt & A & P & A & A & A & A & A \\
Express_2010_10.txt & A & A & A & P & A & A & P \\
\hline
\end{tabular}

This data matrix was subjected, in the third step, to MCA using 'FactoMineR' (Lê et al. 2008) in $R$, where the keywords were active variables and the metadata were supplementary. This produced a series of dimensions representing the most 
common patterns of co-occurring keywords across the texts and indicated the association of the newspapers with the dimensions. MCA shows this by assigning contributions and coordinates to each category of a keyword (presence _P and absence_A) for each dimension. For example, Table 2 presents the coordinates and contributions for the categories (presence and absence) of the keyword army for Dimensions 1, 2, and 3. Of these three dimensions, the presence of army contributes to Dimension 2 the most.

Table 2. Coordinates (coord) and contributions (ctr) for the categories (presence and absence) of the keyword army for Dimensions 1, 2, and 3

\begin{tabular}{ccccccc}
\hline & Dim.1 coord & Dim.1 ctr & Dim.2 coord & Dim.2 ctr & Dim.3 coord & Dim.3 ctr \\
\hline army_A & -0.069 & 0.009 & -0.097 & 0.07 & -0.025 & 0.005 \\
army_P & 0.513 & 0.065 & 0.722 & 0.522 & 0.183 & 0.039 \\
\hline
\end{tabular}

Using the MCA results, the fourth step involved interpreting the dimensions through coordinates and contributions. Coordinates reflect the nature of the association between the categories of the keywords in terms of proximity, where keywords distributed in similar ways in the articles have coordinates closer to each other on the same side of the origin, and keywords not distributed in similar ways are positioned on opposite sides of the origin (i.e. one will have a positive coordinate and the other a negative one) (Le Roux \& Rouanet 2010). Hence using the coordinates we looked at patterns of co-occurring keywords across the dimensions. This enabled us to see how certain polysemous words were being used, thereby showing us that the approach was effective in showing that words with two or more meanings often exhibit different co-occurrence patterns for those meanings.

Contributions show which categories of keywords are the most important contributors to the dimensions. In this way, contributions are similar to factor loadings in factor analysis, although they do not have polarity and so the coordinates of the keywords are interpreted in conjunction with their contributions. Specifically, keywords with positive coordinates are interpreted in opposition to keywords with negative coordinates. In line with Le Roux and Rouanet (2010), we only interpreted the categories of keywords contributing above the average contribution, as these represent the most distinguishing patterns of variation.

We interpreted each dimension in turn, starting with the first and continuing until we encountered a dimension from which no coherent discourse could be derived. MCA also assigned each article in the corpus a coordinate and contribution for each dimension. This revealed which articles were most associated with the keyword co-occurrence patterns captured by the dimensions. To interpret the 
discourse associated with the dimension, we manually analysed the texts most strongly associated with that dimension. One analyst (Clarke) analysed all dimensions, with the other two (Brookes \& McEnery) analysing 50\%. Where dimensions were analysed by more than one person, the analyses were carried out independently and the results compared. This took the form of each analyst composing a narrative summary of their interpretation of the dimension, producing descriptive labels for each side of the continuum, and citing examples to support the narrative and labelling. The analyses were then compared, and the similarity of the labels considered, with the description and examples being used as supporting evidence. In all cases where this was done there was broad agreement between the separate analyses and the analysts agreed on one set of labels to apply to the dimension. For example, in Dimension 3 (discussed in 4.2) the two analysts initially presented the competing labels as 'domestic policy versus foreign policy' and 'domestic affairs vs. foreign affairs'. The meaning was essentially the same, hence the final choice of label did not imply a disagreement between the coders.

In total, ten dimensions were explored - the tenth dimension was not coherent. Dimension 1 was simply Short vs. Long texts, which is largely a consequence of examining the presence/absence of features (see Clarke 2019). As this reveals no particular insight into the representation of Islam, nor does it contribute helpfully to the discussion of subregister, we set it aside here. The keywords associated with the positive and negative sides of each dimension are given in Supplemental Materials - Appendix II.

\section{Results}

We now present Dimensions 2-9, in each case describing the discourse associated with the assemblage of keywords which characterise that dimension. These dimensions explain $89 \%$ of the variance in the data using the standard modified rate (Benzécri 1992:412) on the eigenvalues. Our consistent finding is that absences of keywords associated with a particular pole of a dimension tended to have their presences associated with the other pole of the dimension. So, to avoid repetition, we do not comment on the absences in what follows. Throughout our analyses we were sensitive to the possibility that a discourse was linked strongly to a subregister within newspapers. We note whether this was the case in the title of each dimension (link to subregister: yes/no). Finally, we consider in each section the association of the individual newspapers to the dimensions, as identified by including this information as supplementary, which produces an overall coordinate of the texts from the different newspapers for each dimension - similar to factor scores in factor analysis. Thus, we explore whether, in our corpus, each 
dimension is general to the newspapers studied or whether there is notable variation between the newspapers. We also comment on whether there is a notable trend in the placement of the newspapers in the dimension with regards to their political leaning or type (i.e. popular 'tabloid' newspapers versus quality 'broadsheet' newspapers). Note that this approach achieves another layer of disaggregation, from an overview of the newspapers to a view of them relative to one another (full results for each dimension are given in Supplemental Materials Appendix III).

4.1 Dimension 2: War, conflict and terrorism vs. reporting of everyday life and events (link to subregister: Yes)

Dimension 2 is interpreted as opposing keywords which, on the positive side, are used in news reports discussing War, Conflict, and Terrorism with keywords on the negative side used in opinion pieces and/or feature articles to discuss everyday life and events. Thus, this dimension not only distinguishes articles by topic, but also by communicative style and subregister.

The keywords strongly associated with positive Dimension 2 include those related to war (e.g. fighters, soldiers, weapons), conflict (e.g. violence, murder) and terrorism (e.g. suicide, bombing, terrorists), as well as keywords which describe people and places (e.g. citizens, members, $m r$, spokesman) and times and dates (e.g. friday, november, yesterday) that are tied to the events being reported. Other keywords depict ongoing investigations (e.g. investigation, emerged, involved, described) and are used in articles reporting on news events related to war, terrorism and conflict, such as the article "Armed police shoot man 'carrying a bomb in a rucksack after he takes a woman hostage' at Brussels tram station as they swoop on terror suspects linked to 'imminent attack in France'" (MailOnline 25.03.16).

By contrast, the keywords strongly associated with the negative Dimension 2 are used to describe entities and encode personal opinions and feelings (e.g. love, kind, hope). Unlike positive Dimension 2, these keywords are not connected by a consistent topic but vary in this regard. However, some of these keywords are used to discuss politics (e.g. brexit, win, politics, ) and business (e.g. job, money, business). Overall, these keywords are used in the articles associated with negative Dimension 2 to encode personal opinions and stances on a range of topics, including politics, work and business, as opposed to war, terrorism and conflict. For example, a Guardian article entitled 'What is an Ideal Childhood?' (17.10.15) asks five celebrities about their views on an ideal childhood. One, the poet Lemn Sissay, talks about the benefit of parents believing in something (politically or religiously), such as the Qur'an, to get the child to think about who they are. 
This first meaningful dimension indicates that the articles in our corpus most commonly vary in terms of those which report on war, terrorism and conflict and those which do not. This dimension, after Dimension 1, represents the best fit of the data, indicating that war, conflict and terrorism is a discourse that is commonly represented in the articles. This is consistent with previous research which found that war and conflict was the most common press discourse of Islam between 1998 and 2009. It also supports Baker et al.s (2013) finding that opinion pieces are an important subregister within which strong stances predominate.

If we look at how the individual newspapers relate to this dimension, we find no overall trend, but the Express (0.2) is most associated with the war, terrorism and conflict discourse, whereas the Sun $(-0.36)$ is most associated with everyday life and events.

4.2 Dimension 3: Foreign Affairs vs. domestic affairs (link to subregister: No)

Dimension 3 is interpreted as opposing keywords on the positive side that are used in reporting on foreign affairs with keywords on the negative side that are used in reporting on local and domestic affairs.

Many of the keywords strongly associated with positive Dimension 3 refer to foreign and UK-based politicians (e.g. mps, trump's, cameron, president), and different countries, places and citizens (e.g. russia, washington, american), which are used to introduce overseas countries and leaders and describe Britain's relationships with them. Many keywords associated with positive Dimension 3 are used to discuss foreign affairs through reference to intergovernmental and political groupings (e.g. eu, un, government, council), while other keywords relate to international military action and war (e.g. military, war, forces). Finally, some keywords are used to report on discussions and negotiations of a foreign affairs nature (e.g. plan, agreement, brexit). Overall, keywords in positive Dimension 3 are used to describe issues relating to foreign affairs, including international trade and agreements, such as the Iran Nuclear Deal, as well as global security and relationships, especially in relation to the rise of ISIS in the context of the Syrian civil war and the refugee crisis. For example, the article entitled "Cameron under Pressure over Claim of 70,000 Anti-ISIS Fighters in Syria as he Pushes for MPs to Back Airstrikes" (MailOnline 1/12/15) outlines the geopolitical and military factors under discussion during a vote in the UK parliament on planned military intervention by Britain in Syria.

By contrast, the keywords strongly associated with negative Dimension 3 report on local incidents and domestic affairs. Many of the keywords refer to crimes and criminal investigations (e.g. died, murder, shot) and to the people 
involved (e.g. brother, father, mother). Some of the keywords associated with negative Dimension 3 denote the locations (e.g. hospital, mosque, school) and times (e.g. began, morning, seven) relating to these events. Other keywords associated with negative dimension 3 include verb forms which encode stance and details of the event (e.g. heard, love, tried, wanted) and often co-occur in articles containing accounts of eyewitnesses or those who knew the individuals involved. Finally, there are keywords referring to social media (facebook, posted, online). Overall, these keywords are used in reports of local terror attacks, domestic affairs such as local crimes, and law enforcement investigations, as in the article "Munich Shooting: Teenage Killer Ali Sonboly 'Inspired by Far-right Terrorist Anders Breivik' and 'Used Facebook Offer of Free McDonald's Food to Lure Victims'" (The Telegraph 24.07.16).

The second most common pattern of variation across the articles in our corpus therefore presents Islam and/or Muslims in relation to either international or domestic affairs. The international affairs are often characterised by global security and international military interventions against ISIS or result from conflict in Syrian, Libyan and Iraq, the refugee/migrant crisis, and trade and nuclear agreements. Domestic affairs often involve descriptions of local terror attacks, such as the London Bridge terror attack in 2017 and those who were injured or killed, as well as forms of local crime, such as domestic abuse. As the second most important dimension, this indicates that Islam is often presented as a global and national security threat, and Muslims as criminal perpetrators.

When we plot each of the newspapers to this dimension we find that, except for the Express (o.11), all tabloid articles (Mirror, The People, Daily Mail, Daily Star, The Sun, The News of the World) are associated with negative Dimension 3, while broadsheets are associated with positive Dimension 3 (Guardian, Independent, The Telegraph, The Times). This indicates that broadsheets tend to focus on foreign affairs, whilst tabloids are more associated with domestic affairs.

\subsection{Dimension 4: Western political conflict vs. overseas conflict (link to subregister: Yes)}

Dimension 4 is interpreted as contrasting Western political conflict on its positive side with overseas conflict on its negative side. The keywords on the negative side link to the subregister travel guides and reviews.

Positive Dimension 4 is characterized by reporting which links Muslims to Western political conflict. The keywords strongly associated with the positive side of this dimension focus on terror attacks (e.g. attack, terror), political processes (e.g. meeting, response) and legal actors/actions (e.g. court, police, prison). Evaluation is apparent (wrong), as is reporting of speech and writing (e.g. read, said, 
told). The Muslim community, and often specifically the British Muslim community, is placed relative to the actors and actions discussed (muslims), especially with respect to hate crimes and discrimination experienced and enacted by them. The political contexts in which these events are situated are Western, more specifically the U.S. (e.g. trump, white house), Europe (eu) and Britain (e.g. labour, parliament, prime minister), and are often placed in time (e.g. tuesday, yesterday). Many of the keywords co-occur in articles discussing the political far-right (right is a keyword) and the anti-Muslim bias expressed by such groups. For example, some articles report on Donald Trump's sharing of anti-Muslim videos posted by the British far-right group, 'Britain First'. Yet not all articles featuring these keywords focus on the persecution of the British Muslim community. Rather, many link to cases where Muslims persecute other groups. For example, some of the articles associated with the positive side of this dimension criticize a political figure's links to Muslims, as in the article "Truly Disgraceful Day for the Labour Party" (The Mail 29.05.19), which links British Labour politician Jeremy Corbyn to a group called 'British Muslims for Corbyn'. The article claims that the posts of the group are 'littered with anti-Semitic tropes', negatively framing both British Muslims and, by association, Jeremy Corbyn as anti-Semitic.

By contrast, negative Dimension 4 focuses on overseas conflict. It is characterized by keywords which reference conflict in terms of scale, the actors involved, and various actions, places and resources linked to conflict. Actions are linked to conflict both overtly (e.g. battle, bombing, war) and indirectly by labeling an action in the conflict (e.g. operation), or by discussing the progress and sequence of actions linked to the conflict (e.g. began, end). These actions are then linked to groups who are engaged, directly or indirectly, in violence (e.g. [saudi] arabia, isis, syria, russia) as well as to actors who are overtly linked to violence (e.g. army, fighters, troops). There is also a clear indication of where the actions being described occur within the area controlled by a group under focus (e.g. border, city, streets). Resources in those areas are also linked to the reporting (e.g. food, oil). The actions or actors involved are often linked to words which give a vague indication of scale (e.g. big, hundred, thousands). Comparative evaluation is also employed on this part of the dimension (e.g. best, better). Overall, these keywords co-occur often in articles that report on the specifics of conflict overseas, principally in the Middle East. The article with the headline "Life in the Shadow of ISIS: Inside the Terror-ruined Towns where Families Face Bombs, Poverty and Deadly Smoke; Families in Iraq are Facing Oil Well Blazes, Fatal Smoke and Hidden IEDs - Months after their Hometowns were Recaptured from ISIS" (The Mirror 03.01.17) shows how this relationship between actions, actors and places occurs in the articles. Here an actor linked indirectly to violence (isis) is operating in an area where resources (oil) are present and violent actions (terror) are impacting on a 
large yet imprecisely quantified group of people. However, many articles associated with negative Dimension 4 are travel guides and reviews, often discussing the beauty and culture of destinations that have been impacted by historical and ongoing conflict.

In summary, Dimension 4 indicates that Muslims and/or Islam are often presented in the national press as security threats, criminal perpetrators (where framed negatively in political disputes) or victims (where framed positively in political disputes). The framing of Muslims as victims in the context of warfare is at best implicit - the religious identity Muslims is a keyword present on the positive side of the dimension, as opposed to the negative, even though the victims of the violent acts described in press articles on the negative side of the dimension are, presumably, predominantly Muslim.

Finally, there is no overall trend between newspaper type or political affiliation and the employment of this discourse. However, the newspaper most associated with western political conflict is the Daily Mail (o.28), whereas the newspapers most associated with employing the discourse of overseas conflict are The People (-0.24) and The Times (-0.24).

\subsection{Dimension 5: UK Policy versus US Policy (link to subregister: No)}

Dimension 5 is interpreted as opposing keywords on the positive side that are used in articles concerning UK policy with keywords on the negative side that are used in articles concerning U.S. policy.

Many of the keywords strongly associated with positive Dimension 5 relate to UK politics (e.g. cameron, mps, party) and crime, law and order (e.g. legal, murder, evidence). Others relate to terrorism and war (e.g. isil, bombing, terrorists), risk (e.g. risk, serious, warned, threat), and Islam (islam, islamist, islamic), while some denote people more generally (e.g. young, human, children). Overall, these keywords are used to discuss UK government policy on topics related to Brexit, crime, prison reform and terrorism, as in the article "I'm a man in a Hurry" (MailOnline 07.10.15) which discusses then-UK Prime Minister David Cameron's new reforms, including policies on extremism and what Islamic schools can teach.

By contrast, many of the keywords strongly associated with negative Dimension 5 are associated with U.S. politics (e.g. trump, washington), armed forces (e.g. military) and foreign affairs. In particular, there are several keywords associated with negative Dimension 5 that refer to negotiations and events (e.g. agreement, conference, talks), particular countries and places (e.g. arabia, city, russia), and temporal information (e.g. monday, late, morning). These keywords are often used in the articles reporting on U.S. policy, especially foreign affairs, trade deals and events involving the President. Several keywords associated with negative 
Dimension 5 encode stance and speech (e.g. according, wrote, reportedly) and refer to media and social media (e.g. press, twitter, news, post). These often occur in the articles reporting on Donald Trump's Twitter activity. Overall, these keywords co-occur in articles that discuss U.S. policy and foreign affairs. Many of the articles associated with the negative side of this dimension discuss Donald Trump's offensive comments on Muslims and his so-called Muslim 'travel ban' policy. They also discuss Trump's actions relating to the Iran nuclear deal and agreement signed by Barack Obama in 2015, and new agreements with North Korea as in the article "'We're Ready to Write a New Chapter between our Two Nations" (MailOnline 12.06.18), which reports on a meeting between Donald Trump and the Supreme Leader of North Korea, Kim Jong-un, to discuss a new agreement for the complete denuclearisation of North Korea.

Thus, the fourth most common pattern of variation involves articles that discuss either UK policy or U.S. policy. The former tends to describe i.) terrorism and policies intended to control and prevent it and ii.) the Prime Minister's or Leader of the Opposition's stance on international military intervention against ISIS. Meanwhile, articles associated with U.S. policy tend to describe the country's foreign relations with Iran and Russia. As the fourth major dimension, it suggests that Islam and Muslims are often discussed in the press as something to be controlled and regulated through policy, both in the U.S. and UK. This contributes to the common discourse of representing Muslims as outsiders.

Finally, there is no overall trend between newspaper type or political affiliation and the employment of this discourse. The newspaper most associated with UK policy is the News of the World (0.2), while the newspaper most associated with U.S. policy is the Daily Mail (-0.19).

\subsection{Dimension 6: Globalisation vs. Tribalism}

Dimension 6 is interpreted as opposing keywords focusing on the positive side on globalisation and the UK's position in the world economy, and on the negative side on tribalism and an Othering of Muslims as 'Them'.

The positive side of this dimension includes keywords relating to UK politics, especially Brexit, which co-occur in articles discussing the effects of the Brexit vote and particular trade deals on the British pound and the world economy more broadly (e.g. brexit, result, vote). A group of keywords refers to the economy and commodities (economy, oil, car, agreement, deal, plans, cut, hit, return), which feature in discussions of the global economy and international trade agreements. Other keywords are used to forecast and predict (e.g. expected, likely, possible) and to refer to business (e.g. team, company, business, agency), and often occur in texts describing and gauging the prosperity of businesses. Many of the keywords are 
evaluative in terms of scale (e.g. biggest, large, major) and there are many temporal and frequency keywords (e.g. days, four, weeks, yesterday), as well as keywords referring to places (e.g. city, local, south). Overall, these keywords often co-occur in texts discussing globalisation, such as a particular country's role and influence in the global economy, various trade agreements, and the success of international businesses in articles such as "FTSE 100 falters but oil prices jump after Iraq says it will 'co-operate' with Opec deal" (The Telegraph 28.11.16).

The keywords on the negative side of Dimension 6 are identity-focused and are used to position groups and identities in opposition to each other in the sense that the identities and characteristics of these groups are presented as being distinct from others. The identities implicated in this are reflected in the keywords and include, among others, iraqi, islamist, mother, muslim, and western. There are keywords referring to U.S. politics (american, barack, trump's, washington), and places and regions in the Middle East (iraq, afghanistan, syria, middle, east). These co-occur in articles describing differences between Western and Middle Eastern culture and practice, presenting these groups as being incompatible and in conflict with each other. Some keywords refer to war and terrorism (e.g. bombing, civil, war). These keywords are occasionally used to distinguish supposedly 'Islamic' terrorists from Muslims as well as to distinguish between different groups in the Syrian Civil war. Various keywords are used in reporting of speech and communicative events (e.g. interview, speak, talk, tell) as well as stance (e.g. kind, love, think), which is used to report one group's opinions of another. Overall, these keywords co-occur in articles associated with the negative side of this dimension to distinguish between different groups and often to position these as being in opposition with each other, such as in the article titled "Adulterous western women are begging to be stoned to death" (The Times 08.10.18), which reports on Haitham al-Haddad's views comparing progressive Western law, culture, and values with 'Islam' and 'Islamic' law, culture and values, in which "all non-Muslims are destined for hell”.

This dimension indicates that the fifth most common pattern of variation involves articles that either discuss globalisation or tribalism. Articles associated with globalisation often discuss the effect of Brexit on the British pound and its status in the global economy, as well as discussing international trade deals, the cost of oil, and international travel to various countries, including Islamic countries. Articles associated with tribalism often distinguish between different groups, e.g. the supposedly lenient treatment of criminal behaviour in Rotherham's Muslim community compared to other UK criminals, and Muslim world/culture/ practices vs. practices of the global West. As the fifth major dimension, it suggests that Islam and Muslims are often presented as interacting and integrating globally (i.e. Islamic governments, companies, and people taking part in trade and 
travel worldwide), as well as being completely distinct and in opposition to nonMuslims or the rest of the world. In this way, Islam and Muslims are either represented as belonging or they are represented as 'Others'.

At its extremes, Dimension 6 opposes left-leaning (The Independent (-0.27), The Guardian (-0.17)) on the negative side with right-leaning newspapers on the positive side (The Sun (o.16), The Express (0.16) and The News of the World (0.2)). However, a right-leaning newspaper (The Times (-0.001)) also appears on the negative side just as a left-leaning newspaper (The Mirror (o.o6)) appears on the positive side. So, while at the extremes of this distribution a trend may be arguable, it does not hold across the distribution.

4.6 Dimension 7: Corruption and human rights vs. The aftermath of terror attacks (link to subregister: Yes)

Dimension 7 is interpreted as opposing keywords on the positive side that feature in articles concerning human rights with those on the negative side that are used in articles concerning the aftermath of terror attacks. The keywords on the positive side of the dimension have a link to one subregister - obituaries.

Many keywords on the positive side of the dimension are associated with human rights and the legal system (e.g. court, justice, life). Another group of keywords refers to particular places and countries (e.g. arabia, church, university), governments and leaders (e.g. conservative, member) and identities (e.g. father, mother, muslim, son). Numerous keywords refer to economy, business and trade (e.g. business, company, economy), temporal and quantity information (e.g. december, july, years), while other keywords are used to draw contrasts and provide extra information (e.g. despite, including, since, although, however). These keywords often occur in texts discussing various human rights concerns from both a positive and negative perspective, such as gay rights, the death penalty, women's rights and violence against women. For instance, several articles positively detail the progressive trend in Saudi Arabia, such as the recent lifting of the ban on women driving and the outlawing of sexual harassment, whilst others negatively emphasise the intolerance of Islam and Islamic countries with frequent executions, corrupt and biased legal systems, and violence against women, such as genital mutilation. Several articles morph into obituaries, detailing the lives of political leaders and their abuse of power. For example, the article "Iran: Seven Key Human Rights Challenges Facing President Rouhani" (The Guardian 04.03.16) reports on President Rouhani of Iran following the success of his moderate allies in recent elections, which meant that Rouhani could focus on human rights violations. The article morphs into an obituary by looking back at previous leaders who tarnished the reputation of Iran before leaving that subregister and 
discussing various human rights challenges that need to be confronted and remedied. Other articles are more explicitly obituaries, such as "Mohamed Morsi, Ousted President of Egypt - obituary" (Telegraph 17.06.19).

By contrast, the keywords strongly associated with negative Dimension 7 are used in articles describing the aftermath of local terror attacks. For example, many keywords refer to terrorism and war, including terrorist groups (e.g. ISIL, ISIS), weapons and terrorist methods of attack (e.g. bombing, suicide), investigations of terror attacks (e.g. footage, incident, scene, suspected) and war (e.g. fighters, ground, syria). Other keywords relate to politics in the UK (e.g. cameron, mps) and the U.S. (e.g. donald, trump) and making statements and comments (e.g. added, comments, twitter). These keywords are often used in reference to government statements and responses following terror attacks, including calls for missile retaliation, resignations, and new policies, such as Trump's 'Muslim ban'. Some keywords are used to report on eyewitness accounts of terror attacks, including through the use of key mental, stance and perception verbs (e.g. know, think, want) and adjectives (e.g. better, big, kind, wrong). Additionally, there are numerous indefinite pronouns (everyone, something, someone, thing, things, anything, everything, anyone) whose strong association with negative Dimension 7 indicates some level of uncertainty about the specifics of the events being reported. Yet, at the same time, other keywords indicate temporal information (e.g. minutes, moment, morning) and various verbs (e.g. happened, let, stand) used to add specific detail about the events. Overall, these keywords co-occur in articles reporting on the aftermath of terror attacks, drawing upon eyewitness reports, government statements and details of the criminal investigation into the attack itself, as in the article "Witnesses reveal moment armed officers stormed Tube station" (MailOnline 04.06.17).

This dimension indicates that the sixth most common pattern of variation involves articles that discuss human rights or which detail the aftermath of terror attacks. As the sixth major dimension, it indicates that Islam and Muslims are often discussed in the national press in terms of being 'behind' on human rights (especially women's rights) or as having caused death and destruction to innocent victims.

Except for the Daily Mail (o.04), Dimension 7 neatly distinguishes tabloid newspapers on the negative side of Dimension 7, with broadsheet newspapers on the positive side. This indicates that, generally, broadsheet newspapers are more likely to focus on corruption and human rights issues, while tabloid newspapers are more likely to focus on the aftermath of terror attacks. 
4.7 Dimension 8: The rise of the far right vs. the radicalisation of British Muslims (link to subregister: No)

Dimension 8 is interpreted as opposing keywords that on the positive side are used to discuss the rise of the far right and its anti-Muslim rhetoric with those on the negative side which are used in articles to describe the radicalisation of Muslims, especially British Muslims.

Many of the keywords strongly associated with positive Dimension 8 are used to refer to the rise of far-right nationalism and the anti-Muslim views that are associated with this (e.g. hate, far, right, muslims, violence). The articles refer to the rise of far-right political parties across various countries (e.g. france, germany), especially as a consequence of Brexit and other political events across the world (e.g. brexit, conservative, supporters). Some keywords are used to refer to the refugee crisis and how the large numbers of refugees migrating to Europe due to the Iraqi and Syrian civil wars has led to growth in support for right-wing parties (e.g. groups, others, people). Several keywords mark scale and importance (e.g. hundreds, mass, thousands) and are often used to enumerate the supporters at various political events. Many keywords refer to religions and religious practices and buildings, especially those relating to Islam (e.g. mosque, muslims, wearing). These terms also often appear in articles referring to far-right social actors expressing anti-Muslim sentiment. Several keywords are used to refer to right-wing criminal incidents and terror attacks against minority groups, especially Muslims (e.g. fire, hate, violence). Some keywords refer to social media and describe how far-right groups meet and share information and post their attacks (e.g. facebook, media, twitter). Overall, these keywords co-occur in articles which discuss, and often critique, the rise of far-right nationalism and its views of 'Others' in articles such as "The age of Trump and 21st century fascism" (The Independent 17.03.17), which argues that populism can steadily evolve into fascism.

Keywords strongly associated with negative Dimension 8 discuss the radicalisation of Muslims. Many of the keywords are used to report on radicalised British Muslims who have fled the UK, leaving their families to join ISIS (e.g. going, join, son). Other keywords refer to the foreign office and its activities (e.g. foreign, secretary, visit), forms of communication (e.g. phone, revealed, sent, spoke), and criminal investigations (e.g. court, information, operation) which are often used to discuss the foreign office's decisions regarding the treatment of British Muslims who joined ISIS but who wish to return to the UK (e.g. return, decision, asked, went). Other keywords associated with negative Dimension 8 refer to temporal information (e.g. months, september, weeks), and general actions (gave, given, involved, received, done, made), which often detail when the individual left, when an event occurred and what took place. Other keywords denote places and 
countries (e.g. afghanistan, iraq, syria, us) and often co-occur in articles describing war and terror attacks carried out by purportedly 'Islamic' groups. Overall, the keywords strongly associated with negative Dimension 8 are used to present the process of Muslims being radicalised. For example, the article "The secret life of Mohammed Emwazi" (The Telegraph 13.11.15) tracks the journey of Mohammed Emwazi (also known as 'Jihadi John') from London to Syria in order to join ISIS. The article describes Emwazi's childhood and education and reports on his life since joining ISIS, including his marriage, his rank within ISIS, and the violence and propaganda videos attributed to him.

The seventh most common pattern of variation across the articles in our corpus thus involves articles that either critique the rise of the far-right and its promotion of anti-Muslim rhetoric, or which promote stories that describe radicalised Muslims, which ultimately contribute to a discourse of fear around Islam.

Except for The Express (0.09) and The Times (-0.1), Dimension 8 opposes Tabloid newspapers on the negative side with Broadsheet newspapers on the positive side. This indicates that reporting on the rise of the far-right is more often associated with broadsheet newspapers, while reporting on the radicalisation of British Muslims is more associated with the tabloids.

\subsection{Dimension 9: Political processes and elections vs. political processes and security threats (link to subregister: No)}

Dimension 9 is interpreted as opposing keywords which on the positive side are used in articles to discuss political processes regarding elections with those on the negative side which discuss political processes regarding security threats.

The positive side of this dimension is about political actors engaged in political conflict during elections. These keywords relate to the political processes feeding into an election where candidates stand, when the election is active they are running, and at the end of the election they may have won or lost in their bid for power. Political actors linked to major parties in the UK are prominent in these keywords and may be identified explicitly (e.g. david cameron), with reference to a role they hold (e.g. defence secretary) or be collectivized (e.g. members, opposition). Other keywords relate to conflict (e.g. battle, campaign, fighting) and co-occur in articles to report on election related conflict, often realized through warfare metaphors, as in the following headline from an article about British politician, Chuka Umunna: "Chuka under fire" (The Mail 15.06.19). While the keywords mostly relate to UK elections, some refer to an Iraqi election, in which the keywords linked to violent actions are used literally, not metaphorically (e.g. died, fighting, fire, killed and shot). 
The dynamic nature of election campaigns is evident in keywords which indicate a highly mobile situation (e.g. back, began, came, left, went). Again, these keywords are often used metaphorically rather than literally. In the election, violent actors are topical - either through discussions of the British army or through discussion of violent conflicts in which the UK is involved with forces in countries such as Syria. Locations relevant to the election are referenced (e.g. city, northern, town, inside). The media are also prominent on the positive side of the dimension (e.g. $b b c$, footage, interview) as their coverage of the election is itself reported on. Additionally, several keywords are public verbs, used to report on direct statements from the actors engaged in the election campaign (e.g. asked, calling, saying). Articles in this part of the dimension also clearly mark the time to which their report is relevant (e.g. minutes, morning, saturday).

The negative side of Dimension 9 relates to political responses to security threats to the UK. The security threats in question are criminal, relating to actors engaged in crime or violence (terrorists). Refugees (refugee, refugees) are linked to this security threat. The British economy and public (citizens, public) are the main target of these threats, as is one important resource (money). The public are at risk both in the $U K$ and when they travel to regions which may be identified specifically (e.g. france, germany) or more vaguely (e.g. across, world). In response to these threats, the newspapers offer readers intelligence assessments (e.g. evidence, safe) which they attribute (according, states, says) to expert sources (e.g. intelligence service). Those intelligence assessments often provide advice which is couched in terms of strong modality (must, need). Several keywords are used to talk about how state actors (e.g. authorities, court, police) are reacting to the threat (e.g. act, deal, order, response). The reactions are not always viewed positively, as in the article "New snooping laws will hand sweeping powers to EVERY police force to hack into phones and check web browser histories" (The Mail 01.03.16).

Several keywords associated with negative Dimension 9 refer to the magnitude of the threat (e.g. large, less, often) and its nature (e.g. problem, terror, terrorism). Both states working to mitigate the threat (britain) and those responsible for the threat (islamic state) are named. The naming of politicians in this part of the Dimension is not common, though where it does occur it is linked to Donald Trump's plans to address a supposed security threat from Mexico by building a continent-wide wall (donald, trump, trump's) and Muslim-majority countries by imposing a travel ban.

This dimension clearly focuses on two features of the same process - politics. Muslims are related to both of these features, becoming issues in election campaigns and being the focus of reporting in relation to political responses to terrorism. The dimension links metaphorical violence in election campaigns (positive) with the literal violence of terrorist acts (negative). An important exception to this 
general situation, however, is that Muslims are linked to literal, not metaphorical, violence in an election campaign happening outside of the UK in a Muslimmajority country (Iraq). Here the representation of Islam is not as negative and, by implication at least, the relation of Islam to violence covers both perpetrator and victim. This contrasts with literal violence on the negative side of the dimension where Muslims are solely perpetrators.

We identified no overall trend between newspaper type or political affiliation and the employment of these discourses. The News of the World (o.19) and The Sun (o.18) are most strongly associated with elections, while The Express (-0.31) is most associated with security threats.

\section{Discussion}

In terms of the goals we set ourselves in the paper, Dimensions 2 to 9 clearly allow us to achieve the goal of refreshing our understanding of the representation of Islam in UK newspapers. The dimensions themselves paint a picture broadly consistent with the results of Baker and McEnery (2019). The success we experienced in achieving our first goal is evidence that we have fulfilled the second - we have demonstrated that MCA may help to organise keywords in a way that facilitates a corpus-assisted discourse analysis. Importantly, the problem of aggregation in keyword studies is dealt with well by the technique. The MCA approach helped us identify meaningful discourses aligned to the groups of keywords on the Dimensions. It also allowed us to identify keywords which linked to multiple discourses but with different senses - battle, for example, is a keyword which contributes to Dimension 4 to refer to literal overseas conflict, such as the 'Battle for Mosul' and Dimension 9 to refer to election processes, such as the metaphorical battle for votes. The MCA technique provided an approach to grouping keywords grounded in statistical co-occurrence and enabled the observation of which articles exhibit these patterns of co-occurrence most and least strongly. While the approach did allow us to consider the issue of absence, in this study at least, that was not a particularly productive avenue of enquiry, as absence and presence seemed largely to be two sides of the same coin.

Of more importance, potentially, our approach successfully highlighted that subregister plays a role in the representation of Islam. The subregisters we identified (in line with Biber \& Conrad 2019) with the assistance of MCA allow us to make some broad claims about the relationship between subregister and discourse. Firstly, not all subregisters link to discourses about Islam in our study. One notable example is letters/texts from readers, which was an important subregister linked to negative representations of Muslims and Islam in Baker et al. 
(2013). By contrast, the link with Opinion Columnists endures, while new links to travel guides and obituaries - have been identified. Hence, we approach a second claim; the engagement of discourses of Islam with subregisters in the UK press is dynamic. While we cannot provide a comprehensive picture of the intersection of Islam and all subregisters in our data, we can comment on those we have seen and those which we know to exist but do not see in our data - and that confirms the interactional and dynamic nature of it. This in turn leads to a third claim that future research can explore - the dynamic interaction between subregister and discourse, in which the two interact to effect, is unlikely to be unique to Islam.

The claims made so far link subregister to effect in discourse, so next we must consider why the interaction exists and what its role in discourse is. In Baker et al. (2013), the subregister of letters to the editor played a role in the discourse - it was a legitimation strategy. What of the new subregisters identified here - why have obituaries become important to the representation of Islam and Muslims? The explanation is given in the discussion of Dimension 7 - pieces which appear to be obituaries are, in fact, strongly evaluative and use the subregister not to celebrate the life or lives in question, but to condemn them. In other words, they are delegitimation strategies. This is highly marked in the context of the obituary subregister, which normally serves 'the double purpose ... of informing the general public of the demise of a well-known individual, and that of celebrating the contribution that the person has made to society' (Pinna \& Brett 2018: 123). In this case, the appearance of the subregister within reportage is to reverse both of those purposes - it is telling the public about the death of a person with whom they are unfamiliar and simultaneously damning that person's contribution to society. So, the link between discourse and subregister is shown, once again, to connect clearly to discourse and to achieving specific effects within it. This finding echoes Biber and Conrad's (2019:46) suggestion, made when discussing shifts of subregister within a conversation, that such a 'switch in purpose can be regarded as a shift in subregister from one kind of conversation to another' and that these shifts in purpose across different kinds of communication, including writing and speech, can be identified within the linguistic characteristics. We see precisely this sort of shift in our data: a shift to the obituary subregister within reportage signals a change of purpose within an article. The situated nature of that switch inverts our expectations of what that subregister normally achieves, with the identification of the subregister in this case allowing the identification of distinct purposes that differentiate between specific subregisters (Biber \& Conrad 2019).

Of course, we can question whether it is possible to determine newspaper subregisters, either automatically or using metadata in some suitably encoded corpus, to add further utility to the approach to keywords taken in this paper. The 
metadata approach can be dismissed swiftly - the news consolidation service we used to compile the data for this study, LexisNexis, does not provide reliable subregister data. Even if it did, the subtlety of the results for Dimension 7 should not be overlooked - there we had evidence that texts appearing to be reportage can, in fact, have embedded within them a substantial portion of text that is, effectively, in another subregister - in this case, obituary. This would provide a challenge both for news producers and automated systems which try to assign subregisters to articles. For example, while the articles do provide a broad topic categorization for an article and the section of the newspaper in which the text occurred, the mapping of subregisters to this information is, at best, highly imprecise. Hence the approach taken here is to place on the analyst the burden of identifying subregisters while accepting that the technique used to cluster keywords helps in this process. What would help this process further would be a comprehensive study of the subregisters of newspaper texts - however, there is no such study that we are aware of.

A final issue that we should consider is the limitations we inherited from previous studies. As noted in Section 2, we used a keyword detection method used in previous studies - yet since those studies were published other approaches to calculating keywords have been proposed, notably that of Egbert and Biber (2019). While future work could adopt such an approach, we anticipate that the differences that it produces would be of limited scale as the key innovation of that approach, a consideration of dispersion, has been acknowledged here by setting a threshold for keywords appearing in at least five percent of files in the corpus, hence eliminating the most egregious cases of ill-dispersed but frequent words creating keywords. Such a simple approach to dispersion, as is common in the key-keyword approach, was shown by Egbert and Biber to produce results similar to their technique, hence we expect differences to be matters of degree rather than absolutes.

\section{Conclusion}

This paper has introduced a new approach to conducting keyword analysis, which explores discourse through the lens of keyword co-occurrence in texts. Our analysis, which employed this approach to explore representations of Muslims and Islam in ten years of national newspaper coverage, identified the major dimensions that characterise this coverage through the qualitative exploration of co-occurring keywords in context, related to representational discourses. These dimensions, and their associated discourses, have indicated relative stability compared to the discourses described by Baker et al. (2013) and Baker and McEnery 
(2019). That is to say, though recent years have witnessed the emergence of new social actors, groups, contexts and events in reportage around Islam, representations continue to Other Muslims, by presenting them as especially violent and as adopting values and practices framed as different from those of the global West. This is a bleak outlook, but it is one that speaks to the power of these representations, such that they endure regardless of the specific people, places and events that are newsworthy at a given time.

Yet our analysis has highlighted one area of significant change. The approach introduced in this paper proved of value in accessing the intersection of subregister and discourse in a corpus in which subregister was not explicitly marked. Through this analysis, we were able to link the presence of particular subregisters to representational discourses. As well as confirming an earlier interaction between a subregister (e.g. opinion pieces) and discourse, we also saw the use of the subregister obituary as a rhetorical strategy, with texts invoking this latter subregister serving, we argue, as a delegitimatory function by discrediting the life and contribution of deceased Muslim social actors. It is notable that this rhetorical effect was often achieved by one subregister embedded within another (reportage). The overall effect, we argue, is a subversion of readers' usual expectations of the functions of obituaries.

The approach to keyword categorisation and analysis introduced in this paper has proven to be effective for providing a more nuanced account of keywords that is sensitive to the various senses and discourses that a single keyword can exhibit across the texts of a corpus. This approach helps to overcome the issue of keyword aggregration that is frequently present in corpus-assisted discourse studies. Such a consideration is relevant to studies of corpora comprising texts from different news outlets, as news reporting is an 'argumentative discourse genre' (Richardson 2004:227) and different news outlets can deploy a single (key)word when invoking distinct, even oppositional, discourses. Our analysis also suggests that it may benefit (corpus-assisted) discourse analysts to account for the role of subregister in their analyses. Again, this is of particular relevance to studies of news texts, which comprise multiple subregisters. Accounting for the interaction between subregister and discourse could represent a fruitful avenue of inquiry for researchers working in a critical vein, as our analysis has demonstrated the potential for news producers to subvert the conventions of particular subregisters for the purposes of working potentially discriminatory discourses into their writing, and in sections of the news where readers - and perhaps more importantly, media monitors - would not usually expect to encounter them.

This paper necessarily presents a series of first steps in using the technique we have introduced. The most obvious next step, given that the keywords were extracted sequentially, is to track the Dimensions through time, and this work is 
underway (Clarke et al. forthcoming). Additionally, given that we used one keyword approach to force a fit of our results to previous studies, it would clearly be of interest to use different approaches to calculating keywords, whether that be in terms of the equation or comparison corpus used, to consider the extent to which these meaningfully change the dimensions identified in this paper. Finally, we have demonstrated here how MCA may be used when texts cannot be reliably analysed using standard MDA. There are other approaches that we could have taken, such as sparse Principal Component Analysis (PCA; Zou et al. 2006), which is sensitive to texts with more than one instance of a keyword. Future work comparing and contrasting the output of MCA and sparse PCA is thus clearly another fruitful avenue future work in this area may take. Finally, the intersection of discourse and subregister which is apparent, though not fully explored in this paper, suggests that a systematic approach to coding subregister in a large dataset would be of value to those interested in discourse analysis and (sub)register analysis alike.

\section{Funding}

Research funded by a grant from the Aziz Foundation to Tony McEnery and Gavin Brookes. The work was also supported by The ESRC Centre for Corpus Approaches to Social Science, ESRC grant number ES/Roo8906/1

\section{References}

Baker, P., Gabrielatos, C., \& McEnery, T. (2013). Discourse Analysis and Media Attitudes: The Representation of Islam in the British Press. Cambridge: Cambridge University Press. https://doi.org/10.1017/CBO9780511920103

Baker, P., \& McEnery, T. (2019). The value of revisiting and extending previous studies: the case of Islam in the UK press. In R. Scholtz (Ed.), Quantifying Approaches to Discourse for Social Scientists (pp. 215-249). Basingstoke: Palgrave Macmillan. https://doi.org/10.1007/978-3-319-97370-8_8

Bednarek, M. (2006). Evaluations in Media Discourse: Analysis of a Newspaper Corpus. London: Continuum.

Biber, D. (1988). Variation across speech and writing. Cambridge: Cambridge University Press. https://doi.org/10.1017/CBO9780511621024

Biber, D., \& Conrad, S. (2019). Register, Genre and Style (2nd edition). Cambridge: Cambridge University Press. https://doi.org/10.1017/9781108686136

Biber, D., \& Gray, B. (2013). Being specific about historical change: The influence of subregister. Journal of English Linguistics, 41(2), 104-134. https://doi.org/10.1177/0075424212472509 
Biber, D., Johansson, S., Leech, G., Conrad, S., \& Finegan, E. (1999). Longman Grammar of Spoken and Written English. Harlow: Longman.

Benzécri, J.P. (1979). Sur le calcul des taux d'inertie dans l'analyse d'un questionnaire. Cahiers de l'Analyse des Données, 4, 377-378.

Brookes, G., \& McEnery, T. (2019). The utility of topic modelling for discourse studies: a critical evaluation, Discourse Studies, 21(1), 3-21. https://doi.org/10.1177/1461445618814032

Carter, R. (1988). The language of written sports commentary: soccer - a description. In M. Ghadessy (Ed.), Registers of Written English. Situational Factors and Linguistic Features (pp. 16-51). London: Frances Pinter, London.

Clarke, I. (2019). Functional linguistic variation in Twitter trolling. International Journal of Speech Language and the Law, 26(1), 57-84. https://doi.org/10.1558/ijsll.34803

Clarke, I., Brookes, G. \& McEnery, T. (Forthcoming). Keywords through time: Tracking changes in press discourses of Islam. International Journal of Corpus Linguistics.

Dunning, T. (1993). Accurate methods for the statistics of surprise and coincidence. Computational Linguistics, 19(1), 61-74.

Lê, S., Josse, J., \& Husson, F. (2008). FactoMineR: An R Package for Multivariate Analysis. Journal of Statistical Software, 25(1), 1-18. https://doi.org/10.18637/jss.v025.io1

Le Roux, B., \& Rouanet, H. (2010). Multiple Correspondence Analysis. London: Sage. https://doi.org/10.4135/9781412993906

Partington, A. (2014). Mind the gaps: The role of corpus linguistics in researching absences. International Journal of Corpus Linguistics, 19(1), 118-146. https://doi.org/10.1075/ijcl.19.1.05par

Pinna, A., \& Brett, D. (2018). Constance and variability: Using PoS-grams to find phraseologies in the language of newspapers. In J. Kopaczyk \& J. Tyrkkö (Eds.), Applications of Pattern-driven Methods in Corpus Linguistics (pp. 107-130). Amsterdam: John Benjamins. https://doi.org/10.1075/scl.82.05pin

Richardson, J.E. (2004). (Mis)Representing Islam: The Racism and Rhetoric of British Broadsheet Newspapers. Amsterdam: John Benjamins. https://doi.org/10.1075/dapsac.9

Schroeter, M. \& Taylor, C. (2018). Exploring Silence and Absence in Discourse: Empirical Approaches. London: Palgrave Macmillan. https://doi.org/10.1007/978-3-319-64580-3

Zou, H., Hastie, T. \& Tibshirani, R. (2006). Sparse Principal Component Analysis. Journal of Computational and Graphical Statistics, 15(2), 265-286.

https://doi.org/10.1198/106186006X113430

\section{Supplemental Materials}

Supplemental materials can be found online: https://doi.org/10.1075/rs.20024.cla.additional 


\section{Address for correspondence}

Tony McEnery

Lancaster University

Bailrigg Lancaster LA1 4 YW

England

a.mcenery@lancaster.ac.uk

Xian Jiaotong University

No. 28 Xianning West Road

Xian, Shaanxi 710049

P.R. China

(iD) https://orcid.org/oooo-0oo2-8425-6403

\section{Co-author information}

Isobelle Clarke

Lancaster University

i.clarke@lancaster.ac.uk

\section{Publication history}

Date received: 30 October 2020

Date accepted: 2 April 2021

Published online: 25 May 2021
Gavin Brookes

Lancaster University

g.j.brookes@lancaster.ac.uk

(iD) https://orcid.org/oooo-0oo3-0726-2559 